\title{
Germinação de sementes de sete espécies medicinais nativas do sul do Brasil
}

\author{
FERREIRA, A.G. ${ }^{1 *}$; ROSA, S.G.T. ${ }^{2}$ \\ Universidade Federal do Rio Grande do Sul, Caixa postal 15015, CEP. 91501-970 Porto Alegre/RS/Brasil \\ *ferreira@pq.cnpq.br, maytenus@terra.com.br
}

\begin{abstract}
RESUMO: Foram verificadas as condições ambientais de temperatura e de luz para germinação de diásporos de Borreria verticillata, Cayponia martiana, Echinodorus grandiflorus, Ocimum selloi, Plantago australis, Polygonum hydropiperoidese Waltheria douradinha. A germinação foi efetuada em placas de petri usando como substrato agar $1 \%$ ou em placas de gerbox com areia, em câmaras $\mathrm{BOD}$, nas temperaturas constantes de 10 e $15^{\circ} \mathrm{C}$ na ausência de luz ou nas temperaturas de 20, 25, 30 e 35ㅇ $\mathrm{C}$ na ausência ou presença de luz branca. Foram usadas ainda, temperaturas alternantes de $10-20^{\circ} \mathrm{C}, 15^{-25^{\circ}} \mathrm{C}, 20-30^{\circ} \mathrm{C}, 25-35^{\circ} \mathrm{C}$, sendo a temperatura mais alta, de cada par, com presença de luz por 9 horas. $B$. verticillata, $E$. grandiflorus e $P$. australis se mostraram com sementes fotoblásticas positivas, enquanto $O$. selloi comportou-se como fotoblástica positiva relativa. C. martiana e $W$. douradinha foram classificadas como afotoblásticas. $P$. hydropiperoides revelou possuir sementes termo-dependentes de temperaturas variáveis obrigatórias, enquanto nas demais espécies, a germinação em temperaturas variáveis ou constantes teve desempenho similar.
\end{abstract}

Palavras-chave: Borreria verticillata, Cayponia martiana, Echinodorus grandiflorus, Ocimum selloi, Plantago australis, P. hydropiperoides, W. douradinha

\begin{abstract}
Seed germination in seven medicinal species native to the south of Brazil. Environmental conditions of temperature and light were verified for diaspore germination in Borreria verticillata, Cayaponia martiana, Echinodorus grandiflorus, Ocimum selloi, Plantago australis, Polygonum hydropiperoides and Waltheria douradinha. Germination was carried out in Petri dishes, using $1 \%$ agar as substrate, or in gerbox containing sand, which were placed into BOD chambers at constant temperatures of 10 and $15^{\circ} \mathrm{C}$ in the absence of light or at $20,25,30$ and $35^{\circ} \mathrm{C}$ in the absence or presence of white light. Alternate temperatures of $10-20^{\circ} \mathrm{C}, 15-25^{\circ} \mathrm{C}, 20-30^{\circ} \mathrm{C}, 25^{-}$ $35^{\circ} \mathrm{C}$ were also tested, as well as the highest temperature in the presence of light during 9 hours/ day. B. verticillata, E. grandiflorus and $P$. australis showed positive photoblastic seeds, whereas $O$. selloiseeds behaved as relative positive. C. martiana and $W$. douradinha seeds were classified as non-photoblastic. P. hydropiperoides seeds were obligatorily dependent on variable temperatures, whereas in the remaining species, germination at variable or constant temperatures was similar. Não mexer no Abstract

Key words: Borreria verticillata, Cayponia martiana, Echinodorus grandiflorus, Ocimum selloi, Plantago australis, P. hydropiperoides, W. douradinha
\end{abstract}

\section{INTRODUÇÃO}

OBrasil abriga uma enorme biodiversidade distribuída por vários biomas e ecossistemas (Silva et al., 2006). A flora é rica em espécies nativas com princípios medicinas ativas e, as quais são largamente utilizadas na medicina popular, sendo que a maioria delas é usada de forma extrativista. À medida que cresce a ocupação humana com uso de novas áreas, esta pressão destrutiva aumenta (Rosa \& Ferreira, 2001). A disponibilização de informações sobre a propagação de espécies medicinais facilitará aos agricultores o cultivo destas plantas, favorecendo o mercado informal de erveiros e os pequenos e médios laboratórios farmacêuticos dedicados à produção de medicamentos de origem vegetal (Farias, 1999).

A propagação de plantas medicinais pode ser efetuada por via assexuada, em alguns casos, ou sexuada, representada pela germinação de sementes (Rosa \& Ferreira, 2001). A luz e a temperatura, além da água e oxigênio, são fatores ambientais de maior importância no fenômeno de

Recebido para publicação em 21/02/2008

Aceito para publicação em 19/02/2009 
germinação de sementes. Fornecidas as condições favoráveis de umidade, luz e temperatura no solo e no ar, haverá a possibilidade de germinação de maior ou menor número de sementes em uma amostra, bem como será regulada a velocidade do fenômeno germinativo (Heydecker, 1977; Mascia-Vieira et al., 2007).

Fitocromos são cromoproteínas que respondem à fluência de irradiância (Takaki, 2001), os quais mediam a germinação de muitas sementes diante das condições de luminosidade (Scopel et al., 1994). A resposta à luz pode manifestar-se por um incremento na germinação (fotoblastismo positivo), enquanto que em outras espécies a ausência de luz é que promove a germinação (fotoblastimo negativo).

A temperatura influi no processo de germinação, principalmente por alterar a velocidade de absorção de água e das reações químicas, as quais irão acionar o desdobramento das reservas e seu transporte para a síntese de substâncias na plântula (Bewley \& Black, 1994). A faixa de temperatura ótima é aquela onde acontece a germinabilidade máxima, registrando-se o percentual mais alto de germinação no menor tempo médio (Labouriau, 1983). Sementes de muitas espécies têm germinabilidade mais alta em temperaturas alternantes do que em temperaturas constantes (Toole, 1973; Thompson \& Grime, 1983).

Existem referências de alguns trabalhos sobre a germinação de sementes de plantas medicinais ocorrentes no Rio Grande do Sul (Rosa \& Barros, 1999; Rosa \& Ferreira, 1998; 1999; 2001). Dando-se seqüência a estes estudos, o presente trabalho examinou a germinação de sementes de mais sete espécies, abaixo caracterizadas:

1- Borreria verticillata, também denominada de poiaia, vassourinha, erva-botão, é utilizada como emética, expectorante e nos tratamentos de diarréias infantis (Simões et al., 1986). É erva ramificada, semiprostrada, com raízes profundas em solos revoltos, ocorrendo em formações campestres ou como ruderal. Contém alcalóides e óleos essenciais entre as substâncias ativas.

2- Cayaponia martiana ou taiuá, é usada na medicina popular como purgativa, depurativa, para distúrbios digestivos e renais e externamente para afecções de pele (Simões et al., 1986). Trepadeira volúvel com gavinhas, folhas alternadas palmitilobas e pubescentes, ásperas ao tato. Os frutos apresentam listras amareladas com até um centímetro de diâmetro. É planta heliófila ${ }_{1}$ aparecendo em formações campestres, roças abandonadas e bordas de mata (Porto, 1974).

3- Echinodorus grandiflorus, conhecida popularmente por chapéu-de-couro é uma planta rizomatoza, de ambientes aquáticos ou paludosos (Irgang \& Gastal Júnior, 1996). As folhas são preparadas na forma de infuso, tintura ou decocto, sendo usadas como depurativos, emolientes, tônicas, diuréticas e anti-reumáticas (Simões et al., 1986).

4- Ocimum selloi, elixir-paregórico ou anis ou alfavaquinha, é usada popularmente como antidiarréico, anti-espasmódica e antiflamatória, propriedades essas observadas em testes pré-clínicos (Vanderline et al., 1994). É uma erva encontrada em locais com vegetação secundária, de propriedades aromáticas com folhas glabras, providas de glândulas oleíferas na face inferior. Ainflorescência é violácea e possui fruto nuculóideo arrendondado (Magalhães, 1997).

5- Plantago australis, conhecida por tanchagem, é erva prostrada ocorrendo no litoral sul do Brasil, em terrenos ricos em matéria orgânica, com folhas inteiras em roseta e paralelinérveas, densamente pilosas (Cordazzo \& Seeliger, 1988). Apresenta escapo floral que origina frutos deiscentes tipo cápsula circuncisa, ovóide a elipsóide (Barroso, 1999). É usada como cicatrizante, antiinflamatória, tendo forte ação bactericida e anti-diarréica (Lopes, 1997).

6- Polygonum hydropiperoides, denominada de erva-de-bicho ou pimenta-d'água, é utilizada na medicina popular como diurética e anti-diarréica (Simões et al., 1986). É uma erva de ramos avermelhados, folhas simples, alternas lanceoladas, apresentando ócrea cilíndrica com margens ciliadas. As flores são pequenas que originam frutos tipo aquênio. É macrófita aquática, ocorrendo em charcos e banhados (Irgang \& Gastal Júnior, 1996).

7- Waltheria douradinha, douradinha-docampo ou malva-brava, é planta subarbustiva ereta ou decumbente, de folhas alternas, pilosas com margens serreadas. Possui inflorescência com flores sésseis em glomérulos densos e globosos e com fruto tipo cápsula bivalva. A planta é usada para combater infecções respiratórias e hipotensora e externamente para lavar feridas (Simões et al., 1986). Desenvolve-se em campos de solos arenosos, formando pequenos grupamentos (Cristobal, 1983).

O objetivo do presente trabalho foi verificar a influência das temperaturas constantes e alternadas, combinadas à presença ou ausência de luz, na germinação de sementes de sete espécies de plantas medicinais ocorrentes no sul do Brasil.

\section{MATERIAL E MÉTODO}

Sementes ou frutos de Borreria verticillata (L.) G.F.W.Mayer (Rubiaceae); de Cayaponia martiana Cogn. (Cucurbitaceae); de Echinodorus grandiflorus (Cham \& Schltdl.) Micheli (Alismataceae); de Ocimum selloi Benth. (Laminaceae); de Plantago australis Lam. (Plantaginaceae); de Polygonum hydropiperoides Mich. (Polygonaceae) e de Waltheria 
douradinhaA. St.-Hil. (Sterculiaceae) foram colhidas em vários locais no Rio Grande do Sul, estado do Brasil, entre os anos de 1997 e 1998 (detalhes de coleta em Rosa, 2000).

Depois do beneficiamento, foram medidos os teores de umidade $\left(105^{\circ} \mathrm{C} \pm 2\right.$ por 24 horas $) \mathrm{de}_{2}$ no mínimo 20 sementes com duas repetições além do peso de mil sementes para as sete espécies estudadas (Brasil, 1992).

Sementes ou diásporos recém coletados foram definfestados com hipoclorito de sódio a 1\% de cloro ativo por dez minutos, seguidos de enxágüe com água estéril. As semeaduras foram realizadas em condições assépticas. Como substrato foi usado agar a $1 \%$, acondicionado em placas de petri de nove centímetros de diâmetro (Rosa \& Ferreira, 2000). Areia esterilizada umedecida com água destilada foi usada em placas gerbox para os experimentos de emergência das plântulas. A semeadura ocorreu a aproximadamente um centímetro de profundidade, sendo feitas oito repetições de 25 sementes ou diásporos.

Os testes de germinação foram efetuados em câmaras $B O D$ com temperaturas constantes de 10 e $15^{\circ} \mathrm{C}$ (na ausência de luz) e de 20; $25 ; 30$ e $35^{\circ} \mathrm{C}$ na ausência e presença de luz, com fluxo radiante de cerca de 50 umol m $\mathrm{m}^{-2} \mathrm{~s}^{-1}$. A ausência de luz foi obtida pelo envolvimento das placas com duas folhas aluminizadas. Também foram avaliadas a germinação das sementes nas temperaturas alternantes de 10-

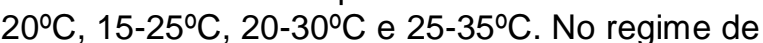
alternância, as sementes permaneceram 15 horas na temperatura mais baixa e 9 horas na mais alta. $A$ germinação foi observada a cada três dias, com uso de luz verde (Rosa \& Ferreira, 2001), a qual pouco afeta o fitocromo (Takaki, 2001). O critério de germinação, em agar, foi o da emissão da radícula com, no mínimo, metade do tamanho da semente, e em areia, a emergência da plântula.

Odelineamento experimental foi inteiramente casualisado com quatro repetições de 25 sementes por tratamento. Os dados foram transformados em arc.sen. $V\urcorner x$, submetidos à análise de variância seguido do teste de Tukey (Sokal \& Rohl, 1997).

\section{RESULTADOE DISCUSSÃO}

As sementes das sete espécies examinadas eram pequenas, de 0,5 a $3,0 \mathrm{~mm}$, e possuíam menos de $10 \%$ de umidade relativa (Tabela 1 ), o que as caracteriza como sementes ortodoxas.

B.verticillata, E. grandiflorus e P.autralis foram fotoblásticas positivas (Tabela 2). A germinação das sementes de E. grandiflorus foi promovida pela alternância de temperatura. Este tipo de comportamento é comum em sementes de espécies de banhado (Grime et al., 1981), em particular, nas Alismataceae (Leck, 1996). As sementes de $B$. verticillata e $P$. australis tiveram características de plantas invasoras, que germinam após o revolvimento do solo quando então são expostas à luz. Além do estímulo da luz, a alternância de temperatura também foi eficaz, indicando que as sementes necessitam da informação que estão próximas à superfície e assim aptas a germinar, emergir e se estabelecer (Thompson \& Grime, 1983). As sementes $P$. australis germinaram em percentuais mais altos a 20 ou $25^{\circ} \mathrm{C}$ na presença de luz ou quando no regime alternante estas temperaturas foram incluídas. Esta espécie, de origem sub-tropical, tem preferência por solos com mais matéria orgânica (Cordazzo \& Seeliger, 1988), sendo as espécies de origem sub-tropical. No gênero Plantago são comuns plantas com sementes fotoblásticas positivas (Pons \& Van der Toorn, 1988).

O. selloiapresentou sementes fotoblásticas positivas, sendo que nas temperaturas de 20 ou $25^{\circ} \mathrm{C}$ na presença de luz, foram os regimes mais favoráveis, embora tanto na ausência de luz, como na alternância de temperaturas tenham mostrado eficiência para a germinação desta espécie (Tabelas 2 e 3). O ótimo de germinação está entre as temperaturas de 25 e $30^{\circ} \mathrm{C}$, tendendo, na ausência de luz, haver menores percentuais de germinação, fazendo com que esta espécie seja classificada como fotoblástica positiva relativa (Ferreira et al., 2001). A amostra apresentou até $65 \%$ de sementes viáveis pelo teste de tetrazólio (resultados não apresentados). Assim ${ }_{2}$ os $63 \%$ de germinação à $25^{\circ} \mathrm{C}$ na luz perfazem $97 \%$ das sementes germinadas, podendo ser considerada como uma germinabilidade alta.

C. martiana e W. douradinha apresentaram sementes neutras (Tabela 2). C. martiana, uma das sete espécies estudadas neste trabalho, foi a que apresentou sementes maiores, com mais massa, germinou tanto na luz, como na ausência desta, assim como em pares alternantes de temperatura, desde que fosse entre 20 e $30^{\circ} \mathrm{C}$. O percentual de germinação não passou de $32 \%$, embora em teste prévio de viabilidade houvesse cerca de $70 \%$ de sementes viáveis. A presença ou ausência de luz não

TABELA1. Conteúdo de umidade e peso de mil sementes de sete espécies de plantas medicinais (B. verticillata, C. martiana, E. gradifolius, O. selloi, P. australis, P. hydropiperoides, $W$.douradinha) nativas sul-brasileiras.

\begin{tabular}{lccccccc}
\hline & B. verticillata & C. martiana & E. grandiflorus & O. selloi & P. australis & $P$. hydropiperoides & W. douradinha \\
umidade (\%) & 6,0 & 8,0 & 7,0 & 6,8 & 5,3 & 9,0 & 5,0 \\
PMS (g) & 0,9 & 26,0 & 0,3 & 0,6 & 0,5 & 1,6 & 0,6 \\
\hline
\end{tabular}


TABELA2. Germinabilidade média (\%) de diásporos entre as temperaturas 10 ou 20 a 35 constantes ou alternantes de $10-20^{\circ} \mathrm{C}, 15-25^{\circ} \mathrm{C}, 20-30^{\circ} \mathrm{C}$ e $25-35^{\circ} \mathrm{C}$ de sete espécies de plantas medicinais na presença ou ausência de luz, usando como substrato agar a $1 \%$.

\begin{tabular}{|c|c|c|c|c|c|c|c|}
\hline Temperatura ${ }^{\circ} \mathrm{C}$ & $\begin{array}{c}B . \\
\text { verticillata }\end{array}$ & $\begin{array}{c}C . \\
\text { martiana }\end{array}$ & $\begin{array}{c}\text { E. } \\
\text { grandiflorus }\end{array}$ & $\begin{array}{c}\text { O. } \\
\text { selloi }\end{array}$ & $\begin{array}{c}P . \\
\text { australis }\end{array}$ & $\begin{array}{c}P . \\
\text { hydropiperoides }\end{array}$ & $\begin{array}{c}W . \\
\text { doudinha }\end{array}$ \\
\hline \multicolumn{8}{|l|}{ Escuro } \\
\hline 10 & $8 \mathrm{e}$ & $0 \mathrm{~d}$ & $0 \mathrm{c}$ & $0 \mathrm{c}$ & $0 \mathrm{~d}$ & $15 \mathrm{bc}$ & $9 \mathrm{~b}$ \\
\hline 15 & $8 \mathrm{e}$ & $8 \mathrm{bcd}$ & $0 \mathrm{e}$ & $25 d$ & $0 \mathrm{~d}$ & $15 b c$ & $23 a b$ \\
\hline 20 & $10 \mathrm{e}$ & $21 a b c$ & $0 \mathrm{e}$ & $41 \mathrm{bcd}$ & $0 \mathrm{~d}$ & $4 \mathrm{bcd}$ & $45 a$ \\
\hline 25 & $10 \mathrm{e}$ & $25 \mathrm{abc}$ & $7 \mathrm{cde}$ & $45 \mathrm{bcd}$ & $0 \mathrm{~d}$ & $0 \mathrm{~d}$ & 38 a \\
\hline 30 & $7 \mathrm{e}$ & $22 \mathrm{abc}$ & $0 \mathrm{e}$ & $29 \mathrm{~cd}$ & $0 d$ & $0 \mathrm{~d}$ & $40 \mathrm{a}$ \\
\hline 35 & $3 e$ & $7 \mathrm{bcd}$ & $0 \mathrm{e}$ & $43 \mathrm{bcd}$ & $0 \mathrm{~d}$ & $0 \mathrm{~d}$ & $46 a$ \\
\hline \multicolumn{8}{|l|}{ Luz } \\
\hline 20 & 38 abcd & $24 a b c$ & $19 a b$ & $49 a b c$ & $95 a b$ & $3 \mathrm{~cd}$ & $31 a b$ \\
\hline 25 & $33 \mathrm{bcd}$ & $29 a b$ & $23 a b$ & 63 a & $96 a b$ & $1 d$ & $41 a$ \\
\hline 30 & $28 d$ & $28 a b$ & $14 \mathrm{bcd}$ & 61 a & $3 d$ & $1 d$ & 39 a \\
\hline 35 & $26 \mathrm{~d}$ & $6 \mathrm{~cd}$ & $1 \mathrm{e}$ & $52 a b$ & $0 \mathrm{~d}$ & $0 \mathrm{~d}$ & $39 a$ \\
\hline \multicolumn{8}{|l|}{ Alternância } \\
\hline $10-20$ & $47 a b c$ & $25 a b c$ & $13 \mathrm{bcd}$ & $26 \mathrm{~cd}$ & 99 a & 69 a & 37 a \\
\hline $15-25$ & $49 a b$ & $32 a$ & $26 a$ & $56 a b$ & $100 \mathrm{a}$ & 71 a & $42 a$ \\
\hline $20-30$ & $55 a$ & $28 \mathrm{abc}$ & $16 a b c$ & $45 \mathrm{bcd}$ & 87 bc & $55 a$ & 48 a \\
\hline $25-35$ & $30 \mathrm{~cd}$ & $22 a b c$ & $5 \mathrm{de}$ & $54 a b$ & $83 \mathrm{c}$ & $16 \mathrm{~b}$ & $34 a b$ \\
\hline
\end{tabular}

letras iguais na coluna, diferenças não significativas ao nível de 5\% (teste de Tukey).

TABELA3. Tempo de germinação, emergência e fotoblastimo de sete espécies de plantas medicinais (B. verticillata, C. martiana. E. grandiflorus, O.selloi P . australis, $P$.hydropiperoides, $W$. douradinha) em substrato agar ou areia (tempo em dias).

\begin{tabular}{|c|c|c|c|c|c|c|c|}
\hline Germinação & $\begin{array}{c}\text { B. } \\
\text { verticillata }\end{array}$ & $\begin{array}{c}\mathrm{C} \\
\text { martiana }\end{array}$ & $\begin{array}{c}\text { E. } \\
\text { grandiflorus }\end{array}$ & $\begin{array}{c}0 . \\
\text { selloi }\end{array}$ & $\begin{array}{c}P . \\
\text { australis }\end{array}$ & $\begin{array}{c}P \\
\text { hydropiperoides }\end{array}$ & $\begin{array}{c}\text { W. } \\
\text { douradinha }\end{array}$ \\
\hline inidal & 3 & 12 & 3 & 3 & 3 & 3 & 3 \\
\hline final & 21 & 33 & 24 & 15 & 9 & 15 & 18 \\
\hline \multicolumn{8}{|l|}{ Emergência } \\
\hline inidal & 3 & $\div$ & 3 & 6 & 6 & 9 & 6 \\
\hline final & 21 & $\div$ & 15 & 21 & 15 & 21 & 21 \\
\hline fotoblastismo & \# & 0 & \# & \# & \# & ao & 0 \\
\hline
\end{tabular}

teve influência sobre a germinação. Foi constatado para sementes de Citrullus lanatus, outra espécie da mesma família, que a testa exerce ação mecânica restritiva à expansão da radícula dificultando a germinação (Thanos \& Mitrakos, 1982). W. douradinha com sementes afotoblásticas, não foi influenciada na sua germinação por alternância de temperatura aos pares ou por diferentes temperaturas constantes.

Os diásporos de $P$. hydropiperoides é outra espécie de banhado, que respondeu de forma quase absoluta à alternância de temperatura(Tabelas $2 \mathrm{e}$ 3). Para a maioria das espécies, a alternância de desta favoreceu o processo germinativo, 
especialmente entre 15 e $25^{\circ} \mathrm{C}$ (Tabela 3). A variação térmica atua no sistema sensor das sementes, diariamente, as quais respondem germinando (Sugahara \& Takaki, 2004). A localização das sementes mais na superfície do substrato, as induz germinar em detrimento daquelas mais enterradas (Thompson \& Grime, 1983).

A germinação e emergência podem ser bastante rápidas, conforme foi verificado em três dias, nas espécies $B$. verticillata e E.grandiflorus. Para C.martiana, espécie com sementes maiores, a germinação foi mais lenta (Tabela 3).

Das sete espécies de plantas medicinais da flora do sul do Brasil estudadas, é possível concluir, quanto à germinação dos diásporos, que três são fotoblásticas positivas, Borreria verticillata, Echinodorus grandiflorus e Plantago australis; Ocimum selloi apresenta sementes fotoblásticas positivas relativas, enquanto que Cayponia martiana e Waltheria douradinha são afotoblásticas. Polygonum hydropiperoides mostrou-se termo-dependente absoluta, germinando suas sementes apenas em temperaturas variáveis. As outras espécies respondem bem a regime variável de temperatura; assim, o plantio dos diásporos pode ser realizado a pouca profundidade no substrato.

\section{AGRADECIMENTO}

À Maria Estefânia A. Áquila, César V. Cordazzo e Arthur G. Fett-Neto pelas sugestões apresentadas. À CAPES pela bolsa de doutorado concedida à Shirley.G.T. Rosa e ao CNPq pela bolsa de produtividade à Alfredo G.Ferreira.

\section{REFERÊNCIA}

BARROSO, G.M. Frutos e sementes: morfologia aplicada à sistemática de dicotiledôneas. Viçosa: Ed. UFV. 1999. 443p.

BEWLEY, J.D.; BLACK, M. Seeds: physiology of development and germination. New York: Plenum Press, 1994. 445p.

BRASIL. Regras para analises de sementes (RAS). Brasília: SNDA/DNDV/CLAV, 1992. 365p.

CORDAZZO, C.V.; SEELIGER, V. Guia ilustrado da vegetação costeira do extremo Sul do Brasil. Rio Grande: Ed.FURGS, 1988. 275p.

CRISTOBAL, C.L. Esterculiáceas. In: REITZ, P.R. Flora ilustrada Catarinensis. Itajaí: Editora Herbário Barbosa Rodrigues, 1983. 57p.

FARIAS, M.R. Avaliação da qualidade de matérias-primas vegetais. In: SIMÕES, M.O. et al. Farmacognosia: da planta ao medicamento. Porto Alegre: Ed. Universidade. Federal do Rio Grande do Sul, 1999. p.197-220.

FERREIRA, A.G. et al. Germinação de sementes de Asteraceae nativas no Rio Grande do Sul, Brasil. Acta Botanica Brasílica, v.15, n.2, p.231-42, 2001.
GRIME, J.P. et al. A comparative study of germination characteristics in a local flora. Journal of Ecology, v.69, p.1017-59, 1981.

HEYDECKER, W. Stress and seed germination: an agronomic view. In: KHAN, A. The physiology and biochemistry of seed dormancy and germination. Amsterdan: Elsevier, 1977. p.237-82.

IRGANG, B.E.; GASTAL JÚNIOR, C.V.S. Macrófitas aquáticas da planície costeira do RS. Porto Alegre: Ed. UFRGS, 1996. 290p.

LABOURIAU, L.G. A germinação das sementes. Washington: OEA, 1983.170p.

LECK, M.A. Germination of macrophytes from a Delaware River tidal freshwater wetland. Bulletin Torrey Botanical Club, v.123, p.48-67, 1996.

LOPES, A.M.V. Plantas usadas na medicina popular no Rio Grande do Sul. Santa Maria: Ed. Incograph, 1997. 49p.

MAGALHÃES, R.G. Plantas medicinais na região do Alto Uruguai-RS: conhecimentos de João Martins Fiúza (Sarampião). 1997. 172p. Dissertação (Mestrado - Área de concentração em Botânica) - Curso de PósGraduação em Botânica, Universidade Federal do Rio Grande do Sul, Porto Alegre.

MASCIA-VIEIRA, D.C.; SOCOLOWSKI, F.; TAKAKI, M. Germinação de sementes de Dyckia tuberosa (Vell.)Beer (Bromeliaceae) sob diferentes temperaturas em luz e escuro. Revista Brasileira de Botânica, v.30, n.2, p.1838, 2007.

PONS, T.L.; VAN DER TOORN, J. Establishment of Plantago lanceolata $\mathrm{L}$. and $P$. nigra $\mathrm{L}$. among grains $\mathrm{I}$. Significance of light for germination. Oecologia, v.75, p.394-9, 1988.

PORTO, M.L. Curcubitaceae. In: SHULTZ, A.R. Flora ilustrada do Rio Grande do Sul, v.8, n.31, p.1-74, 1974. ROSA, S.G.T. Germinação de sementes de espécies medicinais da flora do Rio Grande do Sul. 2000. 203p. Tese (Doutorado em Botânica) - Programa de Pósgraduação em Botânica, Universidade Federal do Rio Grande do Sul, Porto Alegre.

ROSA, S.G.T.; BARROS, I.B. Behavior of Maytenus ilicifolia seeds in different periods and storage conditions. Acta Horticulturae, v.502, p.249-54, 1999.

ROSA, S.G.T.; FERREIRA, A.G. Germinação de sementes de espécies medicinais do Rio Grande do Sul: Bromélia antiachantha Bert., Cuphea carthagenesis (Jacq) Macbride e Talinum patens (Jacq.) Willdenow. Acta Botanica Brasílica, v.12, n.3, p.515-22, 1998.

ROSA, S.G.T.; FERREIRA, A.G. Germination of medicinal plant: Smilax campestris Griseb (Salsaparrilha). Acta Horticulturae, v.502, p.105-11, 1999.

ROSA, S.G.T.; FERREIRA, A.G. Germinação de sementes de plantas medicinais lenhosas. Acta Botanica Brasílica, v.15, n.2, p.147-54, 2001.

SCOPEL, A.L.; BALLARÉ, C.L.; RADOSEVICH, S.R. Photostimulation of seed germination during soil tillage. New Phytologist, v.126, p.145-52, 1994.

SILVA, M.A.S. da et al. Phytochemical and genetic variability of Casearia sylvestris Sw. from São Paulo State Atlantic Forest and Cerrado. Revista Brasileira de Plantas Medicinais, v.8, n.esp., p.159-66, 2006.

SIMÕES, C.M.O. et al. Plantas da medicina popular no Rio Grande do Sul. Porto Alegre: Ed. UFRGS, 1986. 174p. 
SOKAL, R.R.; ROHLF, F.J. Biometry. San Francisco: W.H.Freeman, 1997. 897p.

SUGAHARA, V.Y.; TAKAKI, M. Effects of light and temperature on seed germination in guava ( $P$ sidium guajava L.- Myrtaceae). Seed Science and Technology, v.32, n.3, p.759-64, 2004.

TAKAKI, M. New proposal of classification of seeds based on forms of phytochrome instead of photoblastism. Revista Brasileira de Fisiologia Vegetal, v.13, n.1, p.1037, 2001.

THANOS, C.A.; MITRAKOS, K. Watermelon seed germination. 1. Effects of light, temperature and osmotica. Seed Science Research, v.2, n.3, p.155-62, 1992.
THOMPSON, K; GRIME, J.P. A comparative study of germination responses to diurnally-fluctuating temperatures. Journal of Applied Ecology, v.20, p.14156, 1983.

TOOLE, V.K. Effects pf light, temperature and their interactions on the germination of seeds. Seed, Science and Technology, v.1, p.339-96, 1973.

VANDERLINE, F.A.; COSTA, E.A.; D'ANGELO, L.C.A. Atividades farmacológicas gerais e atividade antiespasmódica do extrato etanólico de Ocimum selloi Benth (elexir paregórico). In: SIMPÓSIO DE PLANTAS MEDICINAISDO BRASIL, 13., 1994, Fortaleza. Resumos... Fortaleza: Universidade Federal do Ceará. 1994. p.157. 